\title{
Evaluation and Bibliographic Analyses of EdLAM Literature to Help Early Career Academics
}

\author{
Seva Demiröz ${ }^{1}$ \\ ${ }^{1}$ Private Arı Schools, Ankara, Turkey \\ Correspondence: Seva Demiröz, Private Arı Schools, Ankara, Turkey.
}

Received: July 7, 2021

doi:10.5539/ies.v14n12p1
Accepted: August 17, $2021 \quad$ Online Published: November 22, 2021

URL: https://doi.org/10.5539/ies.v14n12p1

\begin{abstract}
According to the Organization for Economic Co-operation and Development (OECD) (OECD, 2018), in almost half of the 38 OECD-member countries, most of the decisions about organization of instruction, personnel management, planning and structures, and resource management are taken at the school level. This study focused on understanding the current body of EdLAM knowledge to help doctoral students and early career researchers plan, run, and publish their studies. The terms "educational administration", "educational management", "educational leadership" were used to search the Web of Science database for studies published between 2000 and 2019. The final data set included 1438 articles. Concepts were examined with cooccurrence analysis using the bibliographic analysis tool, VOSViewer. Citation analysis was employed for ascertaining sources of highly cited articles. Results showed that "educational leadership" was the most studied concepts. Compare: A Journal of Comparative and International Education, and Educational Management Administration and Leadership were found to be those journals with the highest average yearly influence.
\end{abstract}

Keywords: bibliographic mapping, educational administration, educational leadership, educational management, science mapping

\section{Introduction}

Academics, especially early career academics, are increasingly being pressured to publish papers in high-quality, leading academic journals (McGrail, Rickard, \& Jones, 2006). This is because this is often considered to be the most highly valued sign of an academic's research productivity and quality (Mulligan, Hall, \& Raphael, 2013; Print \& Hattie, 1997). However, publishing in such journals can be a difficult code to crack as there is considerable variation in understanding across disciplines as to what defines research excellence (Lamont, 2009). Being published in these journals is even harder for authors who have English as a second language (ESL) seeking to publish in high-quality academic journals, which are mostly published in English.

Having an article published as a doctoral student and an early career academic is considered as a positive sign of future publication and citation counts (Horta \& Santos, 2016). This also could affect increased international collaboration and visibility around the world (Thomas, West, \& Rich, 2016). Despite these advantages, doctoral students and early career academics can experience considerable anxiety when writing for peer-reviewed journals. Doctoral supervision, study groups, publications, or writing coaches may be able to provide certain amount of guidance on writing for publication in peer-reviewed journals, which may even relieve a certain amount of their anxiety (Kamler, 2008; Lee \& Kamler, 2008; McGrail et al., 2006; Nagago \& Bukovszki, 2016).

\subsection{Investigating Research Trends in Educational Leadership, Administration, and Management}

According to the Organization for Economic Co-operation and Development (OECD) (OECD, 2018), in almost half of the 38 OECD-member countries, many decisions about organization of instruction, personnel management, planning and structures, and resource management were taken at the school level. Average OECD rating regarding decision making indicated that one third of the decisions that were related to education systems were made by authorities in the school or local district.

Considering results of Program for International Student Assessment (PISA), it could be stated that an education system's overall performance is associated to clearly indicated expectations regarding students and school autonomy (OECD, 2013). "School systems that provide their schools with greater discretion in student assessments, the courses offered, the course content and the textbooks used, tend to be the school systems that 
perform at higher levels on PISA, whatever the causal nature of that relationship." (Schleicher, 2018, p. 109). Additionally, by conducting international comparisons and analyzes, Schleicher (2018) indicated the importance of effective school management and effective leadership approaches for high-performance school systems with high functions for 21 th century students and teachers. These reflections made within the practical dimension of the education emphasized the importance of educational leadership, administration, and management.

Recently, there has been growing interest in the development of the field of educational leadership, administration, and management (EdLAM), with the body of knowledge in EdLAM field having been reviewed with different global approaches, focuses, and regions. These approaches include mixed-methods research (Parylo, 2012), literature reviews (Bellibaş \& Gümüş, 2019; Daniels, Hondeghem, \& Dochy, 2019) and science mapping studies (Hallinger, 2019a, 2019b; Wang \& Bowers, 2016). The focusses of these publications vary including research methods, time, grade levels, and concepts. Different countries and/or regions, such as Asia (e.g., Hallinger \& Bryant, 2013; Hallinger \& Chen, 2015), Africa (e.g., Bush \& Glover 2016; Hallinger 2019a) have also been the subject of corpus analyses of EdLAM reviews.

Despite EdLAM literature having been growing internationally, scholars in the field generally point out that studies on knowledge accumulation in the field have not been getting enough attention (Asuga, Scevak, \& Eacott, 2016). EdLAM scholars, being members of a robust field, took this note seriously, and have conducted review and trend studies that analyze the body of the EdLAM knowledge (e.g. Hallinger, 2019a; Wang \& Bowers, 2016) in order to see the growth of the field and its direction. The basic rational behind these studies, as is the case with the current study, was that knowledge accumulation in EdLAM, gathered through studies and reflection, subsequently affects universities' educational administration programs. If the work that researchers in the field have undertaken contributes to EdLAM, and informs and shapes the discipline's knowledge accumulation, then we may consider these scholarly venues have had an impact on education (Borgemenke \& Brown, 2013).

In an early study, using citation analysis, Haller (1968) examined citations of those articles published in Educational Administration Quarterly (EAQ), investigating the publishing authors' affiliation and academic training. Results showed that educational administration mostly cited from studies in education and sociology. Psychology, social psychology, political science, economics, and anthropology were other fields that were found to contribute to educational administration (Wang, Yinjing, \& Bowers, 2016).

Another early example of citation research in EdLAM was undertaken by Campbell (1979). From 1965 to 1978, 238 articles in EAQ were analyzed to find out the most cited journals in the field. EAQ, Phi Delta Kappan, and the Journal of Educational Administration were the first, second, and third most cited journals, respectively (Wang et al., 2016).

Trend analyses have also been increasing throughout the current decade. Richardson and McLeod (2009) examined articles published in Journal of School Leadership (JSL) and in EAQ between 2000 and 2007 to determine the most cited EdLAM journals. EAQ, JSL, and Phi Delta Kappan were found to be the first, second, and third most cited journals, respectively. Additionally, Richardson and McLeod (2009) indicated that EAQ generally published articles regarding empirical research, theory, and philosophy; however, JSL published on practice, practitioners, and knowledge application.

Using citation analysis, Borgemenke and Brown (2013) analyzed articles published in International Journal of Educational Leadership Preparation (IJELP) between 2006 and 2010 in order to examine the knowledge base of educational leadership; they reported the most cited authors and impact factors.

Using bibliometric and content analysis, 2347 publications from 15 core EdLAM journals were analyzed from 2007 to 2016 to identify thematic strands, major research findings, and limitations in the literature (Tian \& Huber, 2016). The authors present five thematic strands from school leadership for enhancing students' academic achievement and teachers' effectiveness; these strands ranged from the principal's instructional leadership for school improvement to distributed leadership and its impact on organizational climate and teachers' attitudes and stress (Tian \& Huber, 2016).

Hallinger (2019a) examined 292 articles published before the end of 2016. To analyze the EdLAM knowledge base of South African literature, the author analyzed data according to volume, growth, period, distribution across scholarly journals, authors, and citation impact as well as research methods, conceptual models, and topics. Although Hallinger's work mostly concentrated on EdLAM knowledge base those societies outside of the of Anglo-American and Northern-European sphere, he has also contributed to the EdLAM field with science mapping studies. In his most recent studies, Hallinger (2020) examined EdLAM studies in Africa (Hallinger, 2019b), Asia, and Latin America. 
Hallinger (2019b) also studied 645 Scopus-indexed EdLAM documents published between 1960 and 2008. Via science mapping, Hallinger (2019b) examined the geographical distribution of the articles as well as highly cited authors and documents. Hallinger also studied conceptual trends in EdLAM. As a result of these studies, Hallinger (2019b) reports that the most recent concept studied in African EdLAM context appeared to be school leadership.

In his most recent article, Hallinger (2020) worked on the body of EdLAM knowledge in Asia, Africa, and Latin America. Data included 1171 documents published from 1965 to 2018; the results of this study Hallinger (2020) showed that articles from the region selected for the study increased in number between 2015 and 2018. School leadership, school management, and principals were found to be the most recent concepts studied by EdLAM scholars from Asia, Africa, and Latin America.

A further study, conducted Hallinger \& Kovacevic (2019), investigated research on educational administration by reviewing bibliographic mapping, size, growth trajectory, and geographic distribution of EA studies published between 1960 and 2018. In addition, high impact scholars and documents were presented after the analyses. Authors also stated that a paradigm shift, from "school administration" to "school leadership", had occurred over the years studied.

Considering prior research in the field, the current study focused on the following research questions to understand the current body of EdLAM knowledge and help doctoral students and early career researchers to plan, run, and publish their studies:

1) What concepts have been studied between 2000 and 2019 in EdLAM research?

2) What concepts have been studied in relation to one another between 2000 and 2019 in EdLAM research?

3) Which concepts have been gaining increasing interest in the EdLAM research field?

4) Which journals have been cited the most in the EdLAM literature between 2000 and 2019 ?

The current study is distinguished from other studies in the literature because it considers the following features 1) This review mapped the EdLAM literature from 2000-2019; 2) The literature review used herein bibliometric mapping (van Eck \& Waltman, 2010; van Eck \& Waltman, 2017) to conduct a systematic qualitative analysis; 3) This literature review used the search terms "educational administration", "educational management", "educational leadership" and the Web of Science database to gather EdLAM articles.

\section{Method}

To review the body of knowledge of EdLAM bibliographic mapping, in other words science mapping were used. Bibliographic/science mapping is a computational technique facilitating the visualization, analysis, and modeling of a broad range of scientific and technological activities. This is a field lies at the intersection of scientometrics, citation analysis, computer science, information visualization, visual analytics, data mining, and knowledge discovery (Cobo et al., 2011).

The author of the current research used a systematic review method (Stansfield, Dickson \& Bangpan, 2016) to systematize this review in order to better interpret the results and overcome challenges when searching online databases. Deciding to identify resources, searching a source appropriately, evaluating results methodically, deciding which data to grab from each resource, reaching relevant data in a usable format, and deciding what information to record for transparency could be considered as those challenges that researchers may confront if they decide not to follow the systematic method for their review (Stansfield et al., 2016). Along this line, the author used a three-step process, namely: 1) Planning the search, 2) Executing the search, and 3) Screening and managing information. Details of these research steps are explained in Table 1. 
Table 1. Three stages of the study

\begin{tabular}{ll}
\hline Stage & Objective \\
\hline & $\begin{array}{l}\text { The aim of the study was determined in order to review EdLAM knowledge base. } \\
\text { The resource was determined as the Web of Science. } \\
\text { The decision to limit data (publications) to the 2000-2019 period. } \\
\text { VOSviewer was chosen to map and visualize data. }\end{array}$ \\
\hline $\begin{array}{l}\text { Web of Science were searched using the keywords "educational administration", "educational management", } \\
\text { and "educational leadership" to generate a data set for the review. } \\
\text { VOSviewer was run using bibliographic data and publication references. }\end{array}$ \\
$\begin{array}{l}\text { 3. Screening and managing the search } \\
\text { information }\end{array}$ & $\begin{array}{l}\text { Data screening was conducted along with executing the search stage, since it is important to have concise } \\
\text { Certain criteria were set for the VOSviewer to reach inclusive and concise results. }\end{array}$
\end{tabular}

\subsection{Planning the Search}

The study resource was determined as Web of Science database because it is a high-quality database of scientific publications, and because it has a uniformed search tool that enables users to gather and analyze information in timely manner.

The Web of Science database was searched for documents published between 2000 and 2019 using the keywords "educational administration", "educational management", and "educational leadership". The resulting publication list was then narrowed down to include English language articles only. The final data set included 1438 articles.

\subsection{Executing the Search}

To conduct bibliographic mapping to investigate the research questions, data were analyzed by VOSviewer 1.6.12, a bibliometric mapping tool developed by van Eck and Waltman (2010).

A different data type, counting method, and unit of analysis were applied for each research question, and are presented in Table 2.

Table 2. Data type, counting method, unit of analysis, and number of selected terms results for each of the study analyses

\begin{tabular}{ccccc}
\hline Analyses & Data Type & Counting Method & Unit of Analysis & Results \\
\hline Concepts: Co-occurrence & Bibliographic Data & Full Counting & All Keywords & 3626 \\
Journals: Citations & Bibliographic Data & Full Counting & Sources & 510 \\
\hline
\end{tabular}

As can be seen in Table 2, co-occurrence analysis was conducted in order to examine the first three research questions. Citation analysis was deployed for ascertaining sources of highly cited articles, thereby addressing the fourth research question.

\subsection{Screening Records for Relevance}

After the first round of the analyses, certain criteria were introduced in order so that the results could be better interpreted and understood, this is because the initial results of the selected terms were numerous and interpretation of them was very complex. In order to yield more concise results, VOSviewer was run using different limits for each analysis. The criteria for each of these analyses are presented in Table 3.

Table 3. Data type, counting method, unit of analysis, threshold, and number of selected terms results for each of the study analyses

\begin{tabular}{ccccc}
\hline Analyses & Data Type & $\begin{array}{c}\text { Counting } \\
\text { Method }\end{array}$ & $\begin{array}{c}\text { Unit of } \\
\text { Analysis }\end{array}$ & $\begin{array}{c}\text { Selected } \\
\text { Terms }\end{array}$ \\
\hline Concepts/Co-occurrence & $\begin{array}{c}\text { Bibliographic } \\
\text { Data }\end{array}$ & Full Counting & All Keywords & $\begin{array}{c}\text { Minimum number of occurrences of a } \\
\text { keyword=10 }\end{array}$ \\
\hline Journals: Citations & $\begin{array}{c}\text { Bibliographic } \\
\text { Data }\end{array}$ & Full Counting & Sources & $\begin{array}{c}\text { Minimum number of occurrences of a } \\
\text { keyword=7 }\end{array}$ \\
\hline
\end{tabular}


Details of the chosen thresholds and number of selected terms, as seen in Table 3, are explained in the results section below.

\section{Results}

Criteria to reach the commonly studied concepts were set up based on keywords that appeared in ten or more studies. The results of this analysis yielded 109 common concepts. These concepts were closely examined, and general noun phrases, such as "abstract", "article", and "study" were eliminated from subsequent analyses, due to the fact that these phrases did not directly relate to a single topic; therefore, they tended to distort the visualization of the map. A total of 71 concepts remained, the relationships of which are presented in Figure 1.

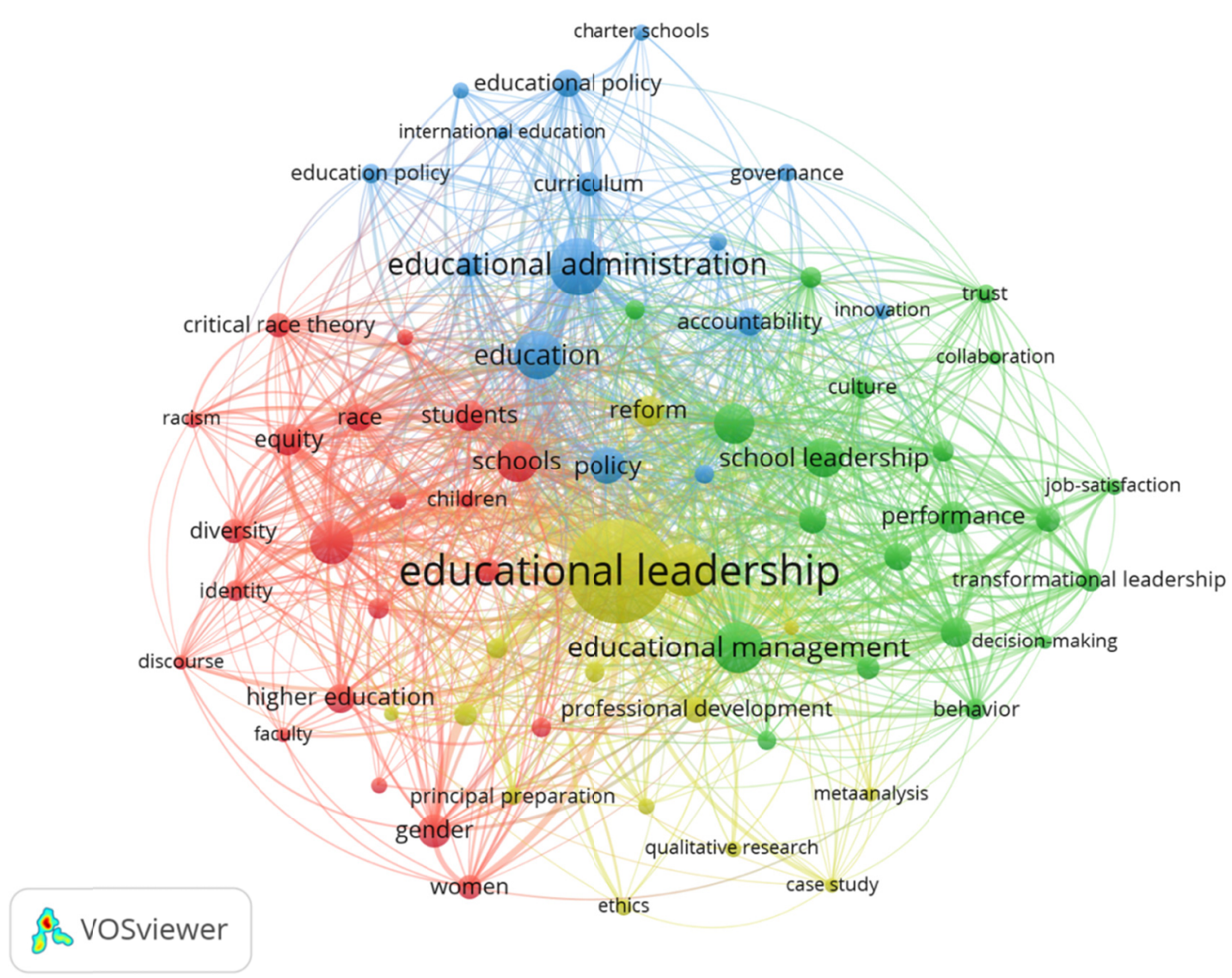

Figure 1. Relationship among the mostly studied concepts in the field

"Educational leadership" was the most studied concept and appeared a total of 526 times in the publications reviewed. "Educational administration" $(\mathrm{N}=165)$, "school principals" $(\mathrm{N}=141)$, "educational management" $(\mathrm{N}=131)$, "education" $(\mathrm{N}=116)$, and "social justice" $(\mathrm{N}=92)$ were found to be the other most-studied concepts in the dataset. Those concepts that occurred least often in the dataset were "discourse" $(\mathrm{N}=11)$, "leadership preparation program" $(\mathrm{N}=11)$, "decision making" $(\mathrm{N}=11)$, and "international education" $(\mathrm{N}=11)$.

The concepts comprised four clusters. Each cluster encompassed concepts related to one another. First cluster included 15 concepts and a leading concept of this cluster was "educational leadership". "School principals" was the most related concept with educational leadership indicating that these two concepts are widely studied together. Fifteen concepts accumulated in the second cluster. "Educational administration" was the leading concept which was mostly found alongside the terms "politics", "education" and "curriculum". Third cluster encompassed 20 concepts, with "educational management" being at the center of the cluster. "Distributed leadership", "school improvement", and "instructional leadership" were the top three concepts that were found in studies on "educational management". The final cluster included 21 concepts, of which "social justice" was in the center, and the most studied concepts were "pedagogy", "resistance", and "diversity". 


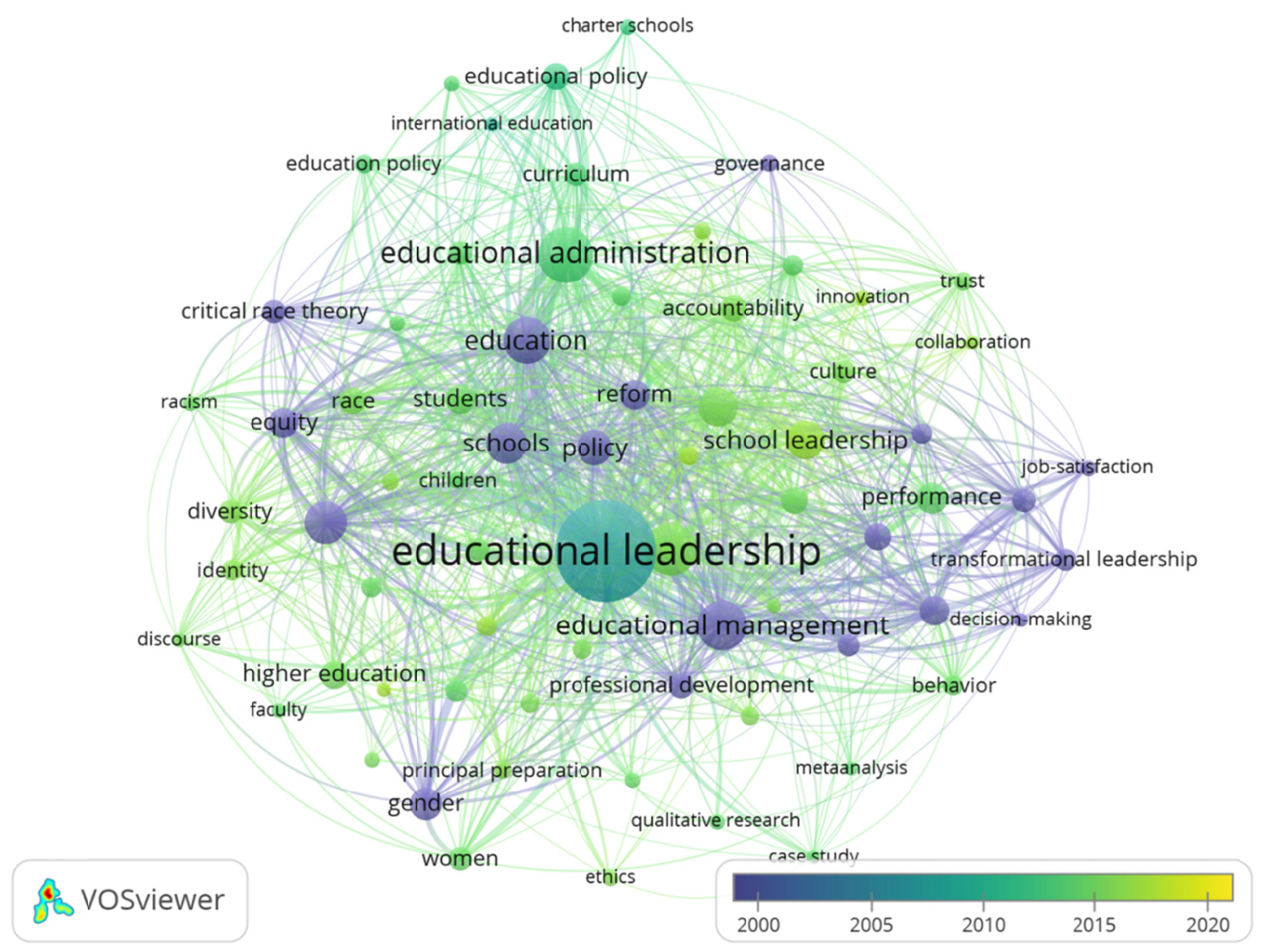

Figure 2. Mostly studied concept according to time

Figure 2 displays the distribution of those concepts studied in the reviewed articles according to time. Studies related to "leadership preparation program", "innovation", and "school leadership" was published more recently than those articles that focused on other concepts. Studies investigating on "governance", "job-satisfaction", and "decision-making" were not found among those articles published after 2001.

To see the most cited journals in the field, citation analysis was applied in consideration of the available sources. Initial analysis yielded 510 different publication outlets in which the articles had been cited. In order to form a more concise picture of those journals in which these research studies had been cited, the minimum number of papers published, and the minimum number of citations in VOSViewer were set at 0 and 7 , respectively. Results yielded a total of 36 sources, of which 28 of were related to one another, as can be seen presented in Figure 3; here, the font and node sizes visually represent the number of publications from the given journals, with larger a font and node sizes indicating a larger number of publications. The clusters represented by different colors and connection lines indicate the closeness among these journals in terms of mutual citations. 


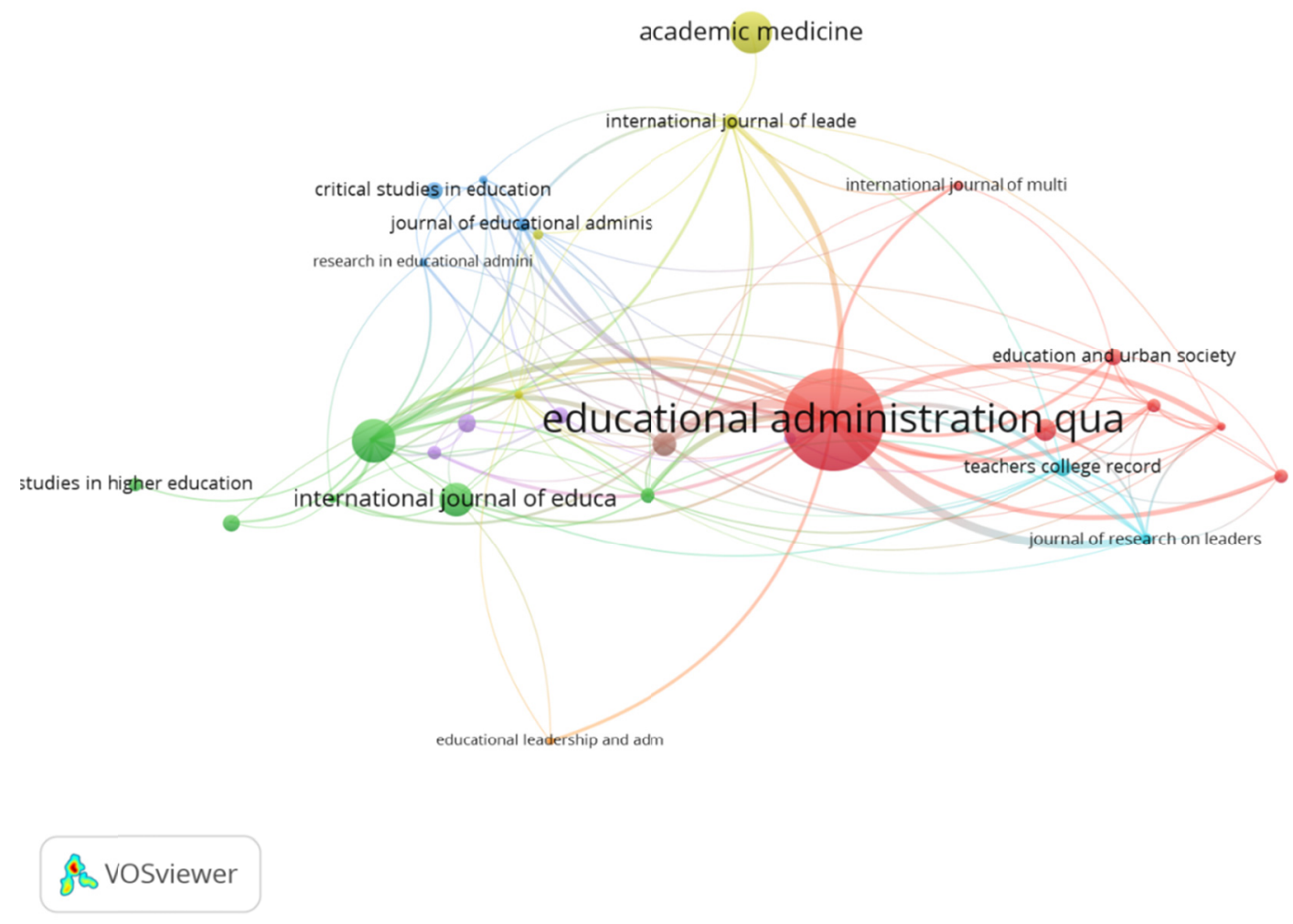

Figure 3. Common cited journals and relationship network

The most frequently (400 or above) cited articles were published in the following journals, respectively: Educational Administration Quarterly $(\mathrm{N}=3797)$, Academic Medicine $(\mathrm{N}=680)$, and the International Journal of Educational Development ( $\mathrm{N}=422)$. In addition to the number of citations, the author also looked at the normalized number of citations of each journal (see Figure 4). Since normalized number of citations is calculated by dividing the total number of citations by the average number of citations published per year, normalized number of citations could prevent a potential misinterpretation from arising, namely, that older documents could gain more time to receive citations when compared with more recent publications (van Eck \& Waltman, 2017). 


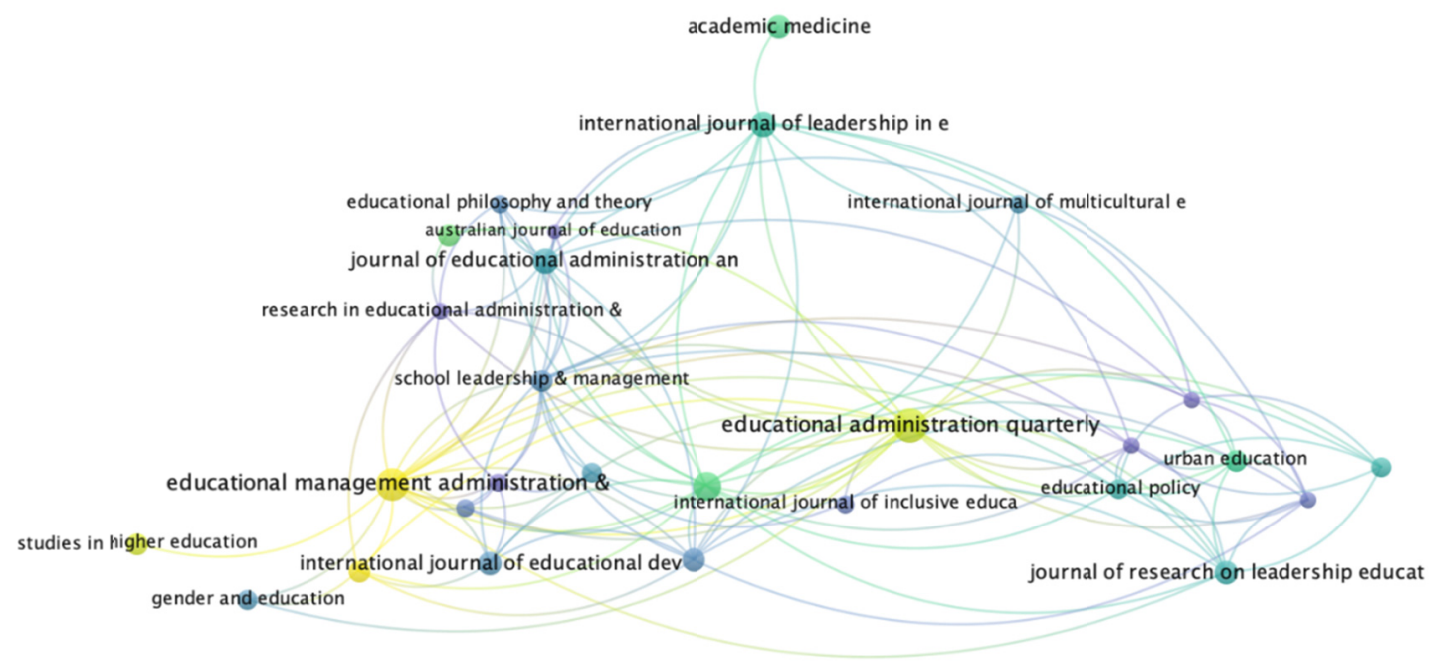

Vosviewer

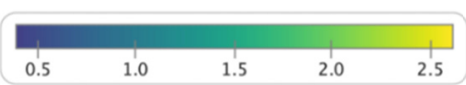

Figure 4. Average normal citation of journals and their relationship

In terms of the average normalized citation, Compare: A Journal of Comparative and International Education, and Educational Management Administration and Leadership were among those journals with the highest average yearly influence, together with a few other journals including Studies in Higher Education, and Educational Administration Quarterly. However, Compare: A Journal of Comparative and International Education, despite the journal having a high number of yearly citations, it did not have a higher than average citation.

\section{Discussion}

The current study reviewed the knowledge base of EdLAM literature using bibliographic mapping. A total of 1438 articles, published between 2000 and 2019, were examined in regard both their citations and the co-occurrence of conceptual terms. Results of this study are discussed in this section.

It was found that educational leadership was the most studied concept in EdLAM literature. This result was unsurprising because "leadership" has been a hot topic in management field in general, and this has naturally affected the EdLAM field. In his most recent articles, Hallinger (2019a, 2019b, 2020) indicated that, today, leadership is the term that is driving the EdLAM field. However, leadership has been approached from different standpoints such as instructional leadership, school leadership, distributed leadership, social-justice leadership and transformational leadership, among others. Bellibas and Gumus (2019) found that leadership was the one of the most studied concepts in Turkish EdLAM literature. Oplatka and Arar (2017) indicate similar results from their review of EdLAM studies in the Arab world. Flessa et al. (2018) report that school leadership as a key topic in Latin America's EdLAM studies. Although leadership has been studied within EdLAM literature, variables and focuses concerning the concept have been varied. As an umbrella term, educational leadership includes all those studies examining leadership research in the EdLAM field, as well as those that, appeared in this review as the most used concepts in EdLAM articles. Since contemporary management approaches have started including leadership as one of their aspects, this result was unsurprising.

Despite the fact that leadership preparation program appeared to be among the least studied concepts it was, in fact, found to be among the most up-to-date terms studied by EdLAM scholars. In similar vein, school leadership and innovation have recently been given considerable attention within the EdLAM field.

The citation analysis carried out in this paper that Educational Administration Quarterly (EAQ) published articles that were frequently cited by EMAL scholars. According to normalized citation analysis, Compare: A Journal of Comparative and International Education, and Educational Management Administration \& Leadership were 
among those journals with the highest average yearly influence.

In another study Richardson and McLeod (2009) examined EdLAM articles published between 2009 and 2007 in EAQ and Journal of School Leadership (JSL). The authors reported that one third of those articles included citations from the publications which were published in these two journals. The other top three journals cited in reviewed articles in EdLAM literature were Phi Delta Kappan, Educational Evaluation, and Policy Analyses and Educational Researchers.

Wang and Bowers (2016) reviewed 5359 articles from 30 EdLAM journals between 2009 and 2013. They reported that EAQ was the most cited journal, and furthermore that the journal has a connection with Educational Research and Reviews in regard to the analysis conducted above. American Educational Research Journal was the second most cited journal and it related to the Journal of Educational Policy.

Hallinger (2020) reported highly cited journals within Asian, Latin American, and African EdLAM literature. The Journal of Educational Admistration and the International Journal of Educational Management were most cited journals. Moreover, Hallinger (2020) indicated that the International Journal of Educational Management and the Journal of Educational Administration were the most welcoming to papers submitted by authors from emerging-EdLAM countries and regions. It was also found that the JEA and EAQ demonstrated the strongest scholarly impact in the field (Hallinger, 2020).

\section{Conclusion}

From a broad perspective, leadership is a prominent concept in the management field. As expected, leadership is a concept that has been extensively studied in the field of education. This finding is important because it shows that researchers in the field of education have been closely following developments and applications of the management field. This can be considered to be a promising development in the field of education because educators, teachers, and educational managers are starting to be accepted as leaders, and educational practices are now being formed according to a leadership framework. Given the fact that "leadership preparation program" and "school leadership" were the mostly studied and associated concepts, it could be said that school administrators are preparing to become effective leaders.

Following leadership, "educational management" and "school principals" were among those most commonly studied concepts in EdLAM. This indicates the importance of the management of the entire school system, as well as the effects and contributions of school principals to that system. This highlights that school administrators and their approaches, attitudes, behaviors, and understandings are all considered within the EMAL field when designing modern school environments, where discussions about student-centered approaches and teachers' roles as facilitators and guides take place.

We might even consider the concept of "school reform" as a shortcoming in the development of the field of education in the current age, an age in which change, and transformation is very fast.

Results of the analyses show that, when compared with other concepts, "school reform" appeared low in number in this current study. Given that, in the current century, change and transformation have been taking place with considerable speed, this could hinder development of the education field. However, "innovation" appeared more often in more recent EdLAM studies, signaling that contemporary research in the EdLAM field has been paying close attention to change and transformation in the field of education and other related fields.

"Globalization" is a concept that has been studied within the educational field in terms of expanding and reproducing good examples in education. It was surprising that "globalization" was among those concepts that were studied less often when compared with other concepts. Considering importance and effects of PISA and TIMSS, which allow for the assessment of education and training globally, it can be expected that "globalization" will, prospectively, be studied with greater regularity within the EdLAM field. Moreover, UNESCO and OECD educational missions, as well as a global common understanding about the importance of education, suggests that EdLAM researchers are paying greater attention to "globalization" than they have done in the past.

One intriguing finding was that "student achievement" was barely studied in recent EdLAM articles. Given the fact that the success and wellbeing of students is widely accepted as one of the main outcomes of education, it is recommended that "student achievement" from the point of educational managers.

\subsection{Limitations}

This study applied the bibliographic mapping technique to examine Web of Science indexed EdLAM articles, and so it has certain limitations. First, it did not include any unpublished research (including, but not limited to dissertations and conference presentation on the topic of EdLAM). The inclusion of such sources may have yielded 
different findings and conclusions. Second, the findings of this study were limited to the Web of Science database. It should be considered that the use of a different database could have resulted in similar or different findings. Third, a search of the Web of Science database was conducted using the terms "educational administration", "educational management", and "educational leadership". Changing these search terms may have yielded different results.

\section{References}

Asuga, G. N., Scevak, J., \& Eacott, S. (2016). Educational leadership, management and administration in Africa: An analysis of contemporary literature. School Leadership \& Management, 36(4), 381-400. https://doi.org/10.1080/13632434.2016.1247042

Bellibaş, M. S., \& Gümüş, S.(2019). A systematic review of educational leadership and management research in Turkey: Content analysis of topics, conceptual models, and methods. Journal of Educational Administration, 57(6), 731-747. https://doi.org/10.1108/JEA-01-2019-0004

Borgemenke, A., \& Brown, C. G. (2013). Examining the educational leadership knowledge base: A 5-year citation analysis. NCPEA Education Leadership Review, 14(1), 1-13.

Bush, T., \& Glover, D. (2016). School leadership and management in south africa: Findings from a systematic literature review. International Journal of Educational Management, 30(2), 211-231. https://doi.org/10.1108/IJEM-07-2014-0101

Campbell, R. F. (1979). Fifteenth anniversary perspective: A critique of the Educational Administration Quarterly. Educational Administration Quarterly, 15(3), 1-19. https://doi.org/10.1177/0013131X7901500303

Cobo, M. J., Lopez-Herrera, A. G., Herrera-Viedma, E., \& Herrera, F. (2011). Science mapping software tools: Review, analysis, and cooperative study among tools. Journal of the American Society for Information Science and Technology, 62(7), 1382-1402. https://doi.org/10.1002/asi.21525

Daniels, E., Hondeghem, A., \& Dochy, F. (2019). A review on leadership and leadership development in educational settings. Educational Research Review, 27, 110-125. https://doi.org/10.1016/j.edurev.2019.02.003

Flessa, J., Bramwell, D., Fernandez, M., \& Weinstein, J. (2018). School leadership in Latin America 2000-2016. Educational Management Administration \& Leadership, 46(2), 182-206. https://doi.org/10.1177/1741143217717277

Haller, E. J. (1968). The interdisciplinary ideology in educational administration: Some preliminary notes on the sociology of knowledge. Educational Administration Quarterly, 4(2), 61-77. https://doi.org/10.1177/0013131X6800400206

Hallinger, P. (1989). Developing instructional leadership teams in secondary schools: A framework. NASSP Bulletin, 73(517), 84-92. https://doi.org/10.1177/019263658907351713

Hallinger, P. (2019a). A systematic review of research on educational leadership and management in South Africa: Mapping knowledge production in a developing society. International Journal of Leadership in Education, 22(3), 315-333. https://doi.org/10.1080/13603124.2018.1463460

Hallinger, P. (2019b). Science mapping the knowledge base on educational leadership and management in Africa, $\begin{array}{llll}\text { 1960-2018. School Leadership \& } & \text { Management, 39(5), }\end{array}$ https://doi.org/10.1080/13632434.2018.1545117

Hallinger, P. (2020). Science mapping the knowledge base on educational leadership and management from the emerging regions of Asia, Africa and Latin America, 1965-2018. Educational Management Administration \& Leadership, 48(2), 209-230. https://doi.org/10.1177/1741143218822772

Hallinger, P., \& Bryant, D. A. (2013). Review of research publications on educational leadership and management in Asia: A comparative analysis of three regions. Oxford Review of Education, 39(3), 307-328. https://doi.org/10.1080/03054985.2013.803961

Hallinger, P., \& Chen, J. (2015). Review of research on educational leadership and management in Asia. Educational Management Administration and Leadership, 43(1), 5-27. https://doi.org/10.1177/1741143214535744

Hallinger, P., \& Heck, R. H. (1996). Reassessing the principal's role in school effectiveness: A review of empirical research 1980-1995. Educational Administration Quarterly, 32(1), 5-44. https://doi.org/10.1177/0013161X96032001002 
Hallinger, P., \& Kovacevic, J. (2019). A bibliometric review of research on educational administration: Science mapping the literature, 1960 to 2018. Review of Educational Research, 89(3), 335-369. https://doi.org/10.3102/0034654319830380

Horta, H., \& Santos, J. (2016). The impact of publishing during PhD studies on career research publication, visibility, and collaborations. Research in Higher Education, 57(1), 28-50. https://doi.org/10.1007/s11162-015-9380-0

Kamler, B. (2008). Rethinking doctoral publication practices: Writing from and beyond the thesis. Studies in Higher Education, 33(3), 283-294. https://doi.org/10.1080/03075070802049236

Lamont, M. (2009). How professors think: Inside the curious world of academic judgement. Cambridge, MA: Harvard University Press. https://doi.org/10.4159/9780674054158

Lee, A., \& Kamler, B. (2008). Bringing pedagogy to doctoral publishing. Teaching in Higher Education, 13(5), 511-523. https://doi.org/10.1080/13562510802334723

McGrail, M., Rickard, C., \& Jones, R. (2006). Publish or perish: A systematic review of interventions to increase academic publication rates. Higher Education Research \& Development, 25(1), 19-35. https://doi.org/10.1080/07294360500453053

Mulligan, A., Hall, L., \& Raphael, E. (2013). Peer review in a changing world: An international study measuring the attitudes of researchers. Journal of the American Society for Information Science and Technology, 64(1), 132-161. https://doi.org/10.1002/asi.22798

Nagago, R. L., \& Bukovszki, E. (2016). Doctoral students' perspectives on academic publishing. EduLingua, 2(1), 1-14. https://doi.org/10.14232/edulingua.2016.1.1

OECD. (2013). Education at a Glance 2013: OECD Indicators. OECD Publishing: Paris. https://doi.org/10.1787/eag-2013-en

OECD. (2018). Education at a Glance 2018: OECD Indicators. OECD Publishing: Paris. https://doi.org/10.1787/eag-2018-en

Oplatka, I., \& Arar, K. (2017). The research on educational leadership and management in the Arab world since the 1990s: A systematic review. Review of Education, 5(3), 267-307. https://doi.org/10.1002/rev3.3095

Parylo, O. (2012). Evaluation of educational administration: A decade review of research (2001-2010). Studies in Educational Evaluation, 38, 73-83. https://doi.org/10.1016/j.stueduc.2012.06.002

Print, M., \& Hattie, J. (1997). Measuring quality in universities: An approach to weighting research productivity. Higher Education, 33(4), 453-469. https://doi.org/10.1023/A:1002956407943

Richardson, J. W., \& McLeod, S. (2009). Where should educational leadership authors publish to get noticed by the top journals in the discipline? Educational Administration Quarterly, 45(4), 631-639. https://doi.org/10.1177/0013161X09331770

Schleicher, A. (2018). World Class: How to Build a 21st-Century School System, Strong Performers and Successful Reformers in Education. OECD Publishing: Paris. https://doi.org/10.1787/9789264300002-en

Stansfield, C., Dickson, K., \& Bangpan, M. (2016). Exploring issues in the conduct of website searching and other online sources for systematic reviews: how can we be systematic? Systematic Reviews, 5, 191. https://doi.org/10.1186/s13643-016-0371-9

Thomas, R., West, R., \& Rich, P. (2016). Benefits, challenges, and perceptions of the multiple article dissertation format in instructional technology. Australasian Journal of Educational Technology, 32(2), 82-98. https://doi.org/10.14742/ajet.2573

Tian, M., \& Huber, S. G. (2019). Mapping educational leadership, administration and management research 2007-2016: Thematic strands and the changing landscape. Journal of Educational Administration, 58(2), 129-150. https://doi.org/10.1108/JEA-12-2018-0234

Van Eck, N. J., \& Waltman, L. (2010). Software survey: Vosviewer, a computer program for bibliometric mapping. Scientometrics, 84(2), 523-538. https://doi.org/10.1007/s11192-009-0146-3

Van Eck, N. J., \& Waltman, L. (2017). Citation-based clustering of publications using CitNetExplorer and VOSviewer. Scientometrics, 111(2), 1053-1070. https://doi.org/10.1007/s11192-017-2300-7

Wang, Y., \& Bowers, A. J. (2016). Mapping the field of educational administration research: a journal citation network analysis. Educational Policy Studies Faculty Publications, Paper 22. 
https://doi.org/10.1108/JEA-02-2015-0013

\section{Copyrights}

Copyright for this article is retained by the author(s), with first publication rights granted to the journal.

This is an open-access article distributed under the terms and conditions of the Creative Commons Attribution license (http://creativecommons.org/licenses/by/4.0/). 